\title{
On the Capillary Eudiometric Apparatus of Bonnier and Mangin for the Analysis of Air in investigating the Gaseous Exchanges of Plants.
}

\author{
BY \\ D. THODAY, M.A. (Camb.), \\ Lecturer in the Physiology of Plants in the University of Manchester. \\ With two Figures in the Text.
}

THE apparatus devised by Bonnier and Mangin for the analysis of air 1 as described by Aubert ${ }^{1}$ and made by M. Golaz, of Paris, has advantages which are especially valuable in investigations of the gaseous exchanges of plants in which determinations of the rate of absorption of oxygen as well as of production of carbon dioxide are desired. The volume of gas required for analysis is only about 0.3 c.c., so that, for instance, small plant organs may be enclosed in a volume of air small enough to ensure that the composition of the air will become measurably altered within a reasonable time. The other principal advantage of the apparatus is the rapidity with which analyses can be made with it; an analysis and the subsequent washing of the apparatus need occupy less than twenty minutes.

This apparatus has found favour in many quarters, and those who have used it have generally expressed themselves well satisfied with the degree of accuracy which they have obtained with it. ${ }^{2}$ On close scrutiny, however, their results hardly justify complete satisfaction.

All the results of analyses of atmospheric air show a deficiency of oxygen amounting to $0.1-0.4$ or more below the correct $20.9 \%$. Bonnier and Mangin themselves ${ }^{3}$ found $20.8 \%$, which agreed with Dumas's determination, the one then current. Curtel, using the new apparatus, ${ }^{4}$ found, however, $0.00 \% \mathrm{CO}_{2}$ and $20.59 \% \mathrm{O}_{2}$, and apparently assumed this throughout

1 Rev. gén. de Bot., iii, I891. Earlier forms of the apparatus are described and precautions discussed by Bonnier and Mangin in Ann. d. sc. nat., Bot., vi, 1 7, 18, 19 ; vii, 2, 3 .

${ }^{2}$ Richards: Annals of Bot., x, I896, p. 536; Palladin: Rev. gén. de Bot., v, I893; Maige: Rev. gén. de Bot., xxi, 1909, p. 32 ; Aubert : Rev. gén. de Bot., iv, 1892, p. 281 ; Nicolas : Ann. d. sc. nat., Bot., ix, 10, I909, p. 25 ; \&c.

3 Ann. d. sc. nat., Bot., vi, I7, I884, p. 2 Io.

4 Rev. gén. de Bot., ii, 1890, p. 7.

[Annals of Botany, Vol. XXVII. No. CVII. July, 1913.] 
his experiments to be the initial composition of the air. Lamarlière, ${ }^{1}$ working in Bonnier's laboratory, found $0.04 \% \mathrm{CO}_{2}$ and $20.60 \% \mathrm{O}_{2}$. Puriewitsch, using Baranetzky's modification of the apparatus, ${ }^{2}$ determined the initial composition of the air in all his experiments, and in these analyses the percentage of axygen is in no case higher than 20.6. Moreover, Stich ${ }^{3}$ says that numerous analyses of atmospheric air (with an older form of the apparatus) differed from Dumas's by $0.2-0.3 \%$.

Some time ago I required such a method of analysis for work on respiration, and Dr. F. F. Blackman suggested this apparatus as possibly a suitable and convenient one if it would give sufficiently accurate results. Earlier trials with it in the Cambridge Botany School had not been altogether successful. ${ }^{4}$ My experience was also unfavourable at first. The directions given by Aubert were closely followed, but a number of difficulties were encountered. These were only overcome by modifying the procedure. Recently, however, I have succeeded in obtaining results, the degree of accuracy of which approaches very nearly to the highest to be expected; I hope, therefore, that this account of the technique adopted may prove of service.

Fig. I illustrates the essential features of the apparatus. By turning the handle $\mathrm{A}$, the piston $\mathrm{B}$ is moved in the cylinder $\mathrm{C}$, which is filled with mercury. In this way an air-thread may be propelled from the graduated part, EF, of the capillary tube into the bent ungraduated part, FG, where absorption takes place, or drawn back into the graduated part again for measurement. The end of the capillary tube opens under mercury in the reservoir $\mathrm{H}$.

The measuring and absorbing regions of the capillary tube correspond to the distinct measuring and absorbing tubes of the earlier forms of the apparatus. The absorbing liquid is drawn into the capillary, from a testtube which is pressed down over the end of the capillary in the reservoir $\mathrm{H}$, and is then expelled, the air being brought into contact with the film of liquid left wetting the walls of the absorbing region. The bulb $\mathrm{D}$ acts as a trap for the gas under analysis to prevent it being inadvertently drawn down into the metal cylinder and there partially lost. It is not to be used for absorption, as stated by Macdougal. ${ }^{5}$ The absorbing solutions should never reach the graduated part of the tube, which is used solely for measurement. ${ }^{6}$

${ }^{1}$ Rev. gén. de Bot., iv, $189^{2}$, p. $48 \mathrm{I}$.

${ }^{3}$ Flora, N.S., xlix, I89I, p. 7 .

${ }^{4}$ Cf. Darwin and Acton: Physiology of Plants, I901, p. 10.

${ }_{5}^{5}$ Textbook of Plant Physiology, I90I, p. 259.

${ }^{6}$ Stoward (Ann. of Bot., I908) found a constant error of -0.86 per cent. in the amount of $\mathrm{CO}_{2}$, and attributes this to potash persistently retained in the bulb! Unless Stoward followed Macdougal's directions it is difficult to understand either how potash got into the bulb at all, or how such a large error could have resulted if the tube and bulb were thoroughly washed out with acid. 
Analyses are carried out rapidly enough for ordinary changes of barometric pressure to be negligible, and the apparatus is so constructed that all the readings for one analysis are taken under appreciably the same pressure of mercury. This is ensured by the horizontal placing of the measuring-tube and by the relatively large surface of the mercury in the reservoir $\mathrm{H}$.

It is, of course, necessary for accurate results that the mercury should move perfectly freely in the tube, and the first difficulty lay in attaining this condition. Even after the mercury had been carefully cleaned, by dropping through dilute nitric acid and finally by distillation in vacuo, a scum appeared when the tube was washed with water after hydrochloric acid, as recommended by Aubert, and this scum it was almost impossible to remove completely. I infer it to be calomel produced by the action of

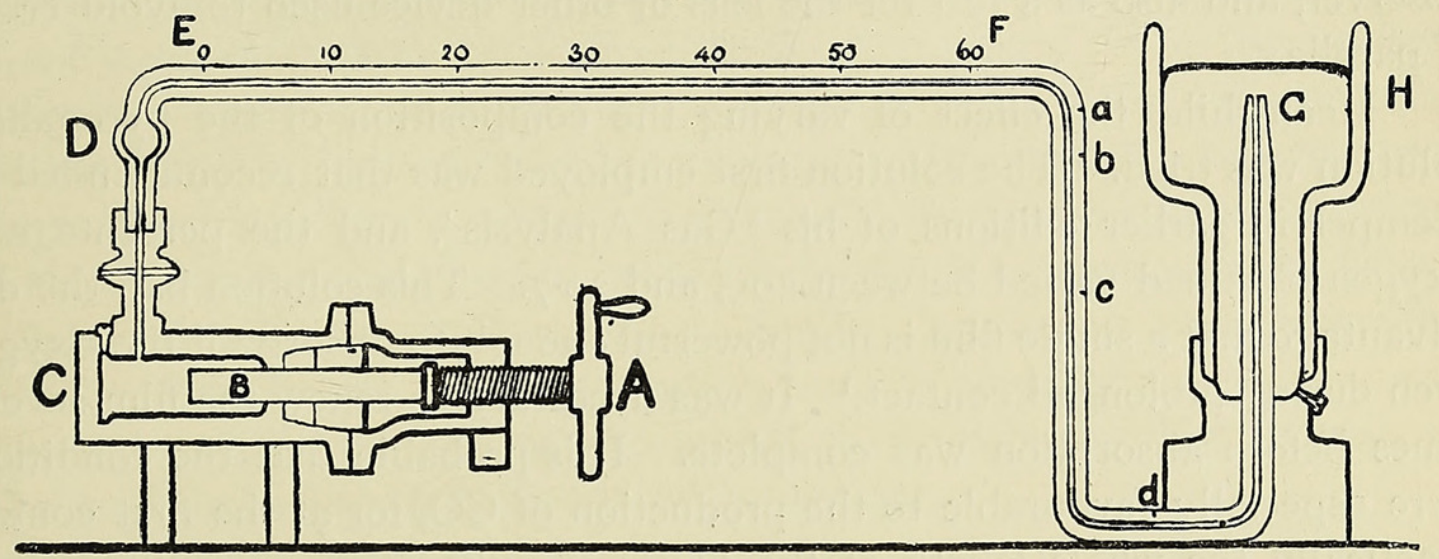

FIG. I.

hydrochloric acid on traces of oxide in the mercury, ${ }^{1}$ and precipitated when the film of hydrochloric acid is diluted with water. When dilute sulphuric acid was used instead of hydrochloric acid this difficulty disappeared, and the washing of the tube was greatly facilitated. ${ }^{2}$

When next the tube is thoroughly washed out with distilled water and - the excess of water is carefully driven out by a series of short mercury threads, the residual film breaks up into drops, and a mercury meniscus no longer moves smoothly, but with a series of jerks. This is avoided if the water used for the final washing contains some sulphuric acid; I have therefore used latterly a $5 \%$ solution of sulphuric acid as the sole washing liquid. The film then left on the walls of the capillary remains unbroken, and a mercury meniscus moves perfectly freely in the tube, vibrating about its position of rest before becoming stationary. The film also serves the purpose of ensuring a constant vapour tension. p. 459 .

1 Berthelot : Comptes Rend., xci, p. 87I ; Barfoed : Journ. f. prakt. Chem. (2), xxxviii, 1888,

${ }^{2}$ It is, of course, necessary to protect the open surface of mercury when the apparatus is not in use, and especially to keep the small amount of dust and oxide which collects on the surface from getting into the capillary. 


\section{Thoday. - On the Capillary Eudiometric Apparatus of}

Notwithstanding the thickness of the walls of the capillary, the volume of air in the apparatus was observed many times to change in a direction corresponding to fluctuations in the temperature of the laboratory; and when the temperature was low an increase of volume was noticed, which might be attributable to the proximity of the observer. The graduated tube was therefore enclosed in a case made of long strips of glass to protect it from draughts, and a cardboard screen interposed between it and the observer. More recently I have surrounded the tube with a trough of water, in order to gain as complete control as possible of any change of temperature which may occur during analysis. Even then changes of $0.1-0.2^{\circ} \mathrm{C}$. were often observed, for which corrections were necessary of \pm 0.03 to 0.07 in the percentage of oxygen, or $\mathrm{CO}_{2}$. Over the trough a long strip of glass is placed, which serves to screen the trough from the breath of the observer, and also as a rest for the lens or other device used to avoid errors of parallax.

Meanwhile, the effect of varying the composition of the pyrogallate solution was tried. The solution first employed was that recommended by Hempel in earlier editions of his 'Gas Analysis', and the percentage of oxygen obtained varied between 20.5 and 20.7 . This solution had the disadvantage that a single film is not powerful enough to absorb all the oxygen even during prolonged contact. ${ }^{1}$ It was necessary to renew the film several times before absorption was complete. It is probable that the conditions were especially favourable to the production of $\mathrm{CO}$, for at the first contact practically the whole length of the film was exhausted; and after it was renewed the portion which the air first met again was exhausted. ${ }^{2}$ Thus it is probable that the production of $\mathrm{CO}$ accounts in part for the large deficit of oxygen obtained with this solution.

In more recent editions Hempel recommends a solution made up with much stronger potash (I $20 \mathrm{grm}$. in 80 c.c. water instead of $60 \%$ ), and with this a series of analyses of atmospheric air gave an average of 20.89 as the combined percentage of $\mathrm{CO}_{2}$ and oxygen. This close approximation to the correct $20.96 \%\left(\mathrm{CO}_{2}+\mathrm{O}_{2}\right)$ I failed, however, to repeat, getting usually about $20.8 \%$.

Similar results were obtained with Haldane's solution, ${ }^{3}$ which is much more powerful and is stated to produce no $\mathrm{CO}$. A single film of this solution nearly suffices for complete absorption, and only requires to be once renewed. It seemed improbable, therefore, that the error was due to the production of $\mathrm{CO}$.

1 Bonnier and Mangin remark on the necessity for repeated contact. Ann. d. sc. nat., Bot., vi, I 8 , I 884 , p. 29 I.

${ }^{2} \mathrm{Cf}$. Müller, on the necessity of slowing down absorption when much oxygen is present, in Abderhalden's Handbuch der biochem. Arbeitsmethoden, iii, p. 624.

3 Methods of Air Analysis, I9I 2, p. I3. Difficulty was found in making a solution of potash of the strength mentioned by Haldane, and the solution used was made up with potash of specific gravity I.5 instead of I.55. Cf. below, p. 570, and see also F. G. Benedict, The Composition of the Atmosphere, Carnegie Institute of Washington, I9 I 2, Pp. 80 and I I I-I3. 
Careful callibration of the tube showed that the error from slight inequalities of bore was between +0.01 and +0.02 in the percentage of oxygen, and therefore practically negligible.

The error did not appear to be due to incomplete absorption. In fact the volume of the residual nitrogen was observed frequently to increase after repeated contact with the absorbing film of pyrogallate of potash. This observation led me to investigate the effect of various purely physical changes, and particularly of the mechanical operations involved in the ordinary procedure. It was found that air introduced into the apparatus and brought repeatedly into the absorbing region of the tube soon began apparently to increase slightly in volume. This change was reversed, on the other hand, if the air was drawn back into the bulb. This empirical result is difficult to explain satisfactorily. There can be little doubt, however, that the apparent changes of volume are caused by movements of the film of moisture which wets the walls of the whole capillary. This film probably tends to accumulate in the horizontal graduated part of the tube, especially as this is at the highest level, a movement which would be accelerated by the encroaching films of absorbing solution. For some reason the transfer of air to the absorbing region tends to favour this accumulation, whereas withdrawal into the bulb tends to hinder it-indeed, to counteract it. Whether this be the true explanation or not, readings taken after withdrawal into the bulb are more constant than readings taken immediately after transfer to and from the absorbing region.

Taking advantage of this observation and always reading the volume after withdrawing the air into the bulb, repeating the process a few times to make sure that the readings were constant, the following results were obtained, after correcting for temperature and introducing the slight callibration correction.

Analyses of a Sample of Atmospheric Air.

\begin{tabular}{|c|c|c|c|c|c|}
\hline $\begin{array}{l}\% \mathrm{CO}_{2} \\
\% \mathrm{O}_{2}\end{array}$ & $\begin{array}{c}(\mathrm{I}) \\
0.04 \\
20.89\end{array}$ & $\begin{array}{c}(2) \\
0.03 \\
20.89\end{array}$ & $\begin{array}{c}(3) \\
0 \cdot 07 \\
20 \cdot 86\end{array}$ & $\begin{array}{c}(4) \\
0 \cdot 03 \\
20 \cdot 88\end{array}$ & $\begin{array}{c}\text { Average. } \\
0.04 \\
20.88\end{array}$ \\
\hline$\%\left(\mathrm{CO}_{2}+\mathrm{O}_{2}\right)$ & & $20 \cdot 9^{2}$ & 20.93 & $20^{\circ} 9^{2}$ & $20 \cdot 9^{2}$ \\
\hline
\end{tabular}

These results agree with one another as closely as can be expected. The maximum difference from the mean percentages is 0.03 , which corresponds to an error of little more than one-tenth of a small graduation less than a millimetre in length.

The average percentage of oxygen, 20.88 , is still somewhat lower than the 20.93 found by Hempel and by Haldane with more elaborate apparatus. In a recent paper Benedict ${ }^{1}$ has given the results of analyses of atmospheric 
air with a new and apparently still more accurate form of apparatus. Results obtained with the same absorbing solution were remarkably concordant, but he found constant differences in the percentage of oxygen according to the particular solution used. With Hempel's solution he obtained $20.85 \%$, with a solution made with rather weaker potash than in Haldane's solution $20.938 \%$, while with Haldane's solution he obtained $20.956 \%$ oxygen. He infers that a small trace of $\mathrm{CO}$ is produced with even slightly weaker solutions as compared with Haldane's solution.

Thus it appears probable that the small deficit which my analyses still show is due, at any rate in part, to the evolution of traces of $\mathrm{CO}$, for the pyrogallate solution was not made up quite according to Haldane's instructions. ${ }^{1}$ The error is small, however, and relatively constant with the solution used in these analyses. Being constant it is for all practical purposes negligible, for it enters into all analyses to appreciably the same extent, and is eliminated when changes of composition are determined by difference. At the same time it appears advisable to use a potassium pyrogallate solution made up accurately according to Haldane's instructions.

The following series of seven analyses of a sample of expired air (which had been retained in the lungs for some seconds) is a further illustration of the degree of concordance obtainable with Bonnier and Mangin's apparatus when used in the way described.

Analyses of Sample of Expired Air.

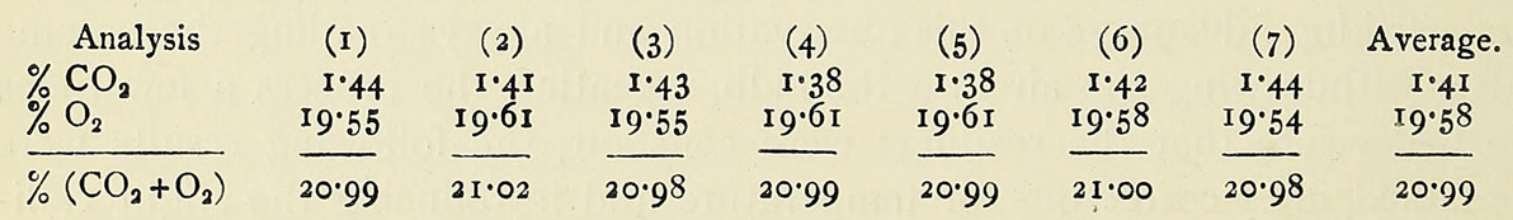

The maximum difference from the mean percentages is $\pm 0.04 \%$, so that a single analysis may be taken to be correct at least to the nearest $0.1 \%$.

In the following résumé of the procedure finally adopted a number of details are given which have not yet been referred to, but which are nevertheless important, as they greatly facilitate the use of the apparatus.

\section{ACCESSORY Apparatus.}

The reagent tubes are fitted with short lengths of glass-rod as handles (Fig. 2). Three are necessary for the reagents, and another (empty) for drying the capillary. Tubes of the same form are convenient for holding the samples of air to be analysed. They can be supported conveniently over small dishes of mercury in small stands of the form shown in Fig. 2,

1 See footnote 3, p. 568 , and references there given. 
which can easily be constructed from copper wire and wood. The wire is bent in such a way that the handles of the tubes are readily removed or pressed into position.

The tubes for the absorbing liquids should have their edges fused in a flame till they just will not go right down over the capillary tube, but stop at the base of the tapering end of it. The acid-tube, on the other hand, as also the air-tubes, should be wide enough to go right down over the capillary so that a thorough neutralization of the absorbing liquid is ensured.

The reagent tubes are most readily filled by first pouring in the reagent to about a centimetre from the open end, and then filling up with clean mercury. On inverting over mercury, the slight escape of liquid is removed with soft tissue or filter paper.

As the absorbing liquids tend to creep out of their respective tubes, the pyrogallate tube should be kept by itself in a separate dish of mercury.

The tubes are transferred to the apparatus closed below by the finger, and pressed down over the end of the capillary tube. On now

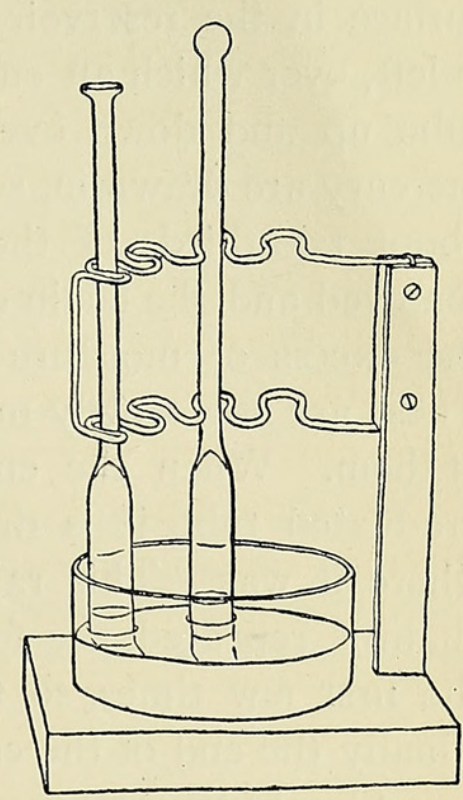

FIG. 2. turning the handle A (Fig. I) in the required direction the liquid or air is drawn into the tube.

\section{REAGENTS.}

Washing liquid: $5 \%$ sulphuric acid. If dilution of the concentrated acid results in the formation of a slight precipitate this should be allowed to settle before use.

Solutions for absorption: (I) A $10 \%$ solution of caustic potash; (2) a solution of potassium pyrogallate, made ${ }^{1}$ by adding 10 grammes of pyrogallol to 100 c.c. of a nearly saturated solution (sp. gr. I.55) of caustic potash (not purified by alcohol ${ }^{2}$ ).

\section{PROCEDURE.}

To clean the apparatus before an analysis a bubble of air is introduced, then clean acid rapidly drawn in as far as zero on the graduated tube. The air-bubble traps any drops of mercury which are left behind where the tube is dirty. The acid is slowly expelled, and again rapidly drawn in, the process being repeated, if necessary with a change of acid, until the mercury

1 See Haldane : Methods of Air Analysis, I9I 2, p. I3; and for further details, Benedict, 1. c., pp. 80 and II 2 .

2 Hempel: Gas Analysis, I9 I I, p. I I5. 
no longer tails off. The tube of acid is then removed, and the acid is blotted from the end of the capillary tube and from the surface of the mercury.

After an analysis acid is drawn in as far as the pyrogallate film has reached, and the contaminated acid washed out a few times. Finally, with clean acid the whole tube is washed out as already described.

A strip of paper is now inserted round the edge of the free mercury surface in the reservoir $(\mathrm{H})$, and, by drawing this across, a clean surface is left, over which an empty tube is inverted. By rapidly moving the testtube up and down over the end of the capillary tube, short threads of mercury are drawn in, separated by bubbles of air. When the chain reaches about two-thirds of the way along the graduated tube the test-tube is removed and the chain drawn rapidly back nearly to the bulb; in this way the excess of moisture in the tube is passed by the mercury threads. These are now slowly moved to the right and they drive the water in front of them. When the end of the chain has moved over a portion of the graduated tube it is drawn rapidly back again; most of the water is left where it was. This rapid backward and slow forward movement of the chain is repeated, the forward movement carrying the chain farther, after the first few times, so that gradually the whole of the chain is expelled. Finally the end of the capillary tube and the mercury surface are blotted.

Should the mercury still not move freely in the tube, ${ }^{1}$ acid may be left in it for some time, or better still a strong solution of potassium cyanide. ${ }^{2}$ The latter should be carefully washed out afterwards with distilled water. Finally the tube is washed as described. If this does not suffice the tube probably needs removing and thoroughly cleaning with nitric acid, \&c., or the mercury itself requires purification.

To make an analysis the air is drawn in to a mark (Fig. I, $c$ ) made halfway up the vertical part of the tube. The sample-tube is removed and the air drawn back till nearly the whole of it is in the bulb. It is now pushed back again, the right-hand end is adjusted accurately to the graduation marked 50 and the position of the other end read; or the adjustment may be approximate and the position of both menisci read. The air is now drawn again into the bulb, again adjusted, and its volume read, and in this way several readings of the volume are made to test their agreement.

The initial volume of the air having been obtained in this way, it is moved along till the right meniscus reaches point $d$ (Fig. I). Potash solution is drawn in to point $a$, and very slowly expelled, till the air comes in contact with the film of potash left on the walls of the tube, the left meniscus being at $a$. If a high percentage of $\mathrm{CO}_{2}$ is expected, the potash is drawn in fairly quickly a second or third time and again very slowly

1 To test this, watch for the vibration of the right-hand meniscus, or compare the readings obtained for the volume of air in the tube when drawn to the left and when pushed to the right.

${ }^{2}$ I am indebted to Dr. A. Lapworth, F.R.S., for suggesting the use of this solution. 
expelled, finally until a drop of mercury is seen to emerge from the end of the capillary tube in the potash solution. The potash is now blotted carefully from the end of the capillary tube under the mercury, the air being driven slightly farther along at the end of the process to make sure that no potash is left in the tube. Now the air is drawn back into the bulb as before, the right meniscus again adjusted to the same point and the volume read; as before, this is repeated a few times or until the readings are constant. ${ }^{1}$

The solution of pyrogallate of potash is drawn in fairly quickly in the same way as the potash solution. The air is brought, not too slowly, into contact with the film of solution. Fresh solution is drawn in and this time very slowly expelled. If much coloration is observed the film may be renewed a second time. Finally the left meniscus is moved to $c$, the tube blotted, and readings of the remaining volume obtained, ${ }^{1}$ as before.

1 N.B. A sudden alteration in the length of the air-thread during measurement means that the absorbing solution has been too quickly expelled; too much has thus been left on the walls of the tube and has gradually collected at one point till it has broken the mercury thread there and altered the pressure of the air. This bubble of liquid must be expelled, and the end of the tube again blotted carefully before the reading of the volume is continued. 


\section{$2 \mathrm{BHL}$ Biodiversity Heritage Library}

Thoday, David. 1913. "On the capillary eudiometric apparatus of Bonnier and Mangin for the analysis of air in investigating the gaseous exchanges of plants." Annals of botany 27, 565-573.

https://doi.org/10.1093/oxfordjournals.aob.a089476.

View This Item Online: https://www.biodiversitylibrary.org/item/237410

DOI: https://doi.org/10.1093/oxfordjournals.aob.a089476

Permalink: https://www.biodiversitylibrary.org/partpdf/319989

\section{Holding Institution}

Smithsonian Libraries

\section{Sponsored by}

Biodiversity Heritage Library

\section{Copyright \& Reuse}

Copyright Status: Not in copyright. The BHL knows of no copyright restrictions on this item.

This document was created from content at the Biodiversity Heritage Library, the world's largest open access digital library for biodiversity literature and archives. Visit BHL at https://www.biodiversitylibrary.org. 